\title{
The impact of targeted therapy on healthcare resource use in patients with metastatic renal cell carcinoma: The University of Sherbrooke experience
}

Hugo Simard, MD; Robert Sabbagh, MD, MSc, FRCSC; Simon Ouellet, MD; Patrick Richard, MD, MSc, FRCSC; Claudio Jeldres, MD, MSc, FRCSC

Department of Surgery, Division of Urology, Centre Hospitalier Universitaire de Sherbrooke (CHUS), Sherbrooke, QC, Canada

Cite as: Can Urol Assoc J 2018 May 14; Epub ahead of print. http://dx.doi.org/10.5489/cuaj.4924

Published online May 14, 2018

$* * *$

\section{Abstract}

Introduction: We assessed the impact of targeted therapies on healthcare resource use and compared treatment regimens used in patients diagnosed with metastatic renal cell carcinoma (mRCC).

Methods: Clinicopathological and administrative data of patients with mRCC from our institution were retrospectively collected from January 2000 to August 2014. Patients were divided into two groups based on the use of targeted therapies. Healthcare resource use (HCRU) data included non-scheduled total number of hospitalizations, total days hospitalized, emergency department visits, and healthcare professional consultations. Each variable was presented with absolute and relative values (i.e., per month of survival). Statistics relied on the use of t-student and Chi-square tests.

Results: Ninety-nine patients were included in the study; 60 were treated with targeted therapy. There were no statistically significant differences between the two groups for demographic features and clinicopathological stage. HCRU analysis revealed an absolute increase in the median number of healthcare consultants (6 vs. 4 ; $\mathrm{p}<0.01$ ) and emergency department visits ( 1 vs. 0 ; $\mathrm{p}=0.02$ ) for the targeted therapy group. However, analysis per month of survival showed the targeted therapy group had fewer consultants ( $0.33 \mathrm{vs.}$ $0.40 ; \mathrm{p}=0.04)$ and hospitalizations ( 0.09 vs. $0.13 ; \mathrm{p}=0.03$ ) than their counterpart. Population size, non-randomization, treatment selection bias, and heterogeneity were the main limitations of this study.

Conclusions: Monthly use of HCRU is lower in mRCC patients treated with targeted therapies. However, because of a greater overall survival, their absolute total HCRU will be higher than those not exposed to targeted agents. 


\section{Introduction}

Kidney cancer is one of the most common types of cancer diagnosed worldwide. It is the third most common urologic cancer among Canadian men and the most common among women (1). In Canada, 6400 new cases are estimated to be diagnosed in 2016 (1). Of these cases, around 33\% will be metastatic at diagnosis, (2). Metastatic spread results in a 5-year survival of $12 \%$ (2).

During the last decade, the development of targeted therapies for metastatic renal cell carcinoma (mRCC) showed significant improvements over classic treatments of IFNalpha and IL-2 regarding overall survival (OS), progression-free survival and patientrelated outcomes including side effects and health-related quality of life (HRQoL) (3-7). However, annual costs associated with these treatments are estimated to be three to four times higher than treatments in the era before targeted therapies utilisation (8-10).

Most reports on targeted therapies have used oncologic and patient-reported outcomes $(3-7,11,12)$. Few studies have analyzed the impact of targeted therapies on health-care resource utilisation (HCRU) $(8,11)$. We believe HCRU could be an objective way to help assess overall quality of life of patients and costs associated with this treatment modality. Therefore, the primary objective of our study was to evaluate the impact of targeted therapies on HCRU in the mRCC population at our center. Secondary objectives were to evaluate the effect of targeted therapies on OS and treatment regimens compliance with the 2015 Canadian consensus statement (13).

\section{Methods}

Study design

This was an institutional review board-approved retrospective study that included all patients ( $\geq 18$ years old) diagnosed with mRCC from January $1^{\text {st, }} 2000$ to August $31^{\text {st, }}$ 2014. Data were retrieved until December $30^{\text {th }}$, 2014. Newly diagnosed patients with mRCC of any histology subtype that received up-front palliative care, surgery, radiotherapy, targeted therapies or combined modalities were included in the study. Patients with another primary cancer were excluded unless a metastasis biopsy confirmed the renal histology. The mRCC population was divided into two groups depending on the use of targeted therapies. Treatment allocations, follow-up schemes and imaging use were based on patients and physicians preferences and represent a real-world treatment scenario of mRCC.

\section{Data collection}

Patients' data regarding demographics, oncologic and HCRU were collected using our center patient's institutional database. The hospital of the University of Sherbrooke is the unique tertiary/quaternary health care provider in this region of Quebec; therefore, virtually all diagnosis, treatments and follow-ups will be catch in our database. 
Demographics data included gender and age at diagnosis; oncologic data included histology type, initial metastasis burden, and Motzer's risk stratification (14). Histology types were collected either from the primary tumor or metastasis pathology report. Initial metastasis spread was devised into three sub-groups: single metastasis, oligometastases (one to five metastasis), and plurimetastases (six or more metastasis).

HRCU variables were collected starting from the diagnosis of mRCC. They included non-scheduled, mRCC related, total number of hospitalisations and emergency department visits, total number of days hospitalized and number of healthcare consultants, including the palliative care team. Healthcare consultants included medical specialties and other health professionals (i.e., physical therapists, social workers, nutritionists, psychologists) involved in the care of the mRCC patients. In addition to the absolute value of each HRCU variable collected, a value per month of survival was calculated to evaluate the predisposition of each group of using health-care resources.

\section{Statistics}

Median values and full ranges were used to present continuous variables while categorical variables were presented using proportions. Categorical variables were compared with chi-square or Fisher's exact tests. Continuous variables were analyzed with Student's t-tests. Moreover, all tests were two-sided, with a significance level set at $\mathrm{p}<0.05$. IBM SPSS Statistics for Windows, Version 22.0 was used for statistical analysis (released 2013, Armonk, NY: IBM Corp.).

\section{Results}

During the study period, 144 new cases of mRCC were diagnosed. Of those, 90 were included in the study. Exclusions were made for incomplete clinicopathological data and/or follow-up ( $n=37)$, concomitant non-RCC malignancy $(n=6)$ and systemic nontargeted therapy treatment regimens $(n=2)$ [Figure 1]. Sixty patients $(n=60,60.6 \%)$ received targeted therapy. Median time from diagnosis to targeted therapy was 1.8 months $(0$ - 29.7). There were no statistically significant differences between the two groups for gender, age, histologic subtype, initial metastatic spread and Motzer's risk criteria ( $p>0.05$, Table 1). Table 2 lists the reasons for the absence of targeted therapy treatment in the non-treated group. The two main reasons for the absence of targeted therapy were end of life/palliative status at diagnosis $(n=10,26 \%)$ and the use of alternative treatment modalities $(n=9,23 \%)$ for the metastasis, mainly surgery and radiotherapy.

Table 3 shows the results regarding HCRU. Targeted therapy use was associated with increased median number of consultants ( 6 vs. $4, \mathrm{p}<0.01$ ), median emergency department visits ( 1 vs. 0, p=0.02) and median OS (16.5 vs. 7.3 months, Breslow=0.01). However, when analyzed per month of survival, the targeted therapy group had less median number of consultants (0.33 vs. $0.40, \mathrm{p}=0.04)$ and hospitalisations ( 0.09 vs. 0.13 
$\mathrm{p}=0.03$ ). No statistical significance was seen in the total number of hospitalisations ( $2 \mathrm{vs}$. $1, \mathrm{p}=0.10$ ) and number of days hospitalised ( 10 vs. $9, \mathrm{p}=0.71$ ). Table 4 shows that HCRU increase trend as the oncologic prognosis worsens.

In the targeted therapy group, multiples regimens were used during the study (Table 5). sunitinib was the most common used first-line therapy (75\%). Second and third line was received by 40 (66.7\%) and 13 (21.7\%) patients respectively and consisted mainly of everolimus. Only five patients (8.3\%) were treated with fourth-line therapy.

\section{Discussion}

In this study, we analyzed the impact of targeted therapy use on HCRU in the mRCC population at our center. The study showed a statistically significant increase in total HCRU with the use of targeted therapies, specifically in terms of healthcare consultants and of emergency department visits. Non-adjusted clinical features may partly explain the HCRU differences, however, the relatively large OS rates difference between the groups may by itself explain the whole HCRU gap (16.5 vs. 7.3 months, Breslow=0.02). Interestingly, the OS rates recorded in our study represent a real-life scenario and survival rates differ from those observed in randomised control trials. For example, the COMPARZ study reported median OS of 29.3 and 28.4 months in its two groups, therefore, HCRU may be even higher in selected population $(16,17)$. To evaluate the effect of OS on HCRU, we analyzed HCRU values per month of survival. Patients without targeted therapy showed higher HCRU in terms of hospitalisations and number of consultants per month of survival. These results acknowledge the importance of considering the OS on HCRU and also suggest a decrease in HCRU per month of survival with the use of targeted therapies. This also implies that health-care costs will follow the same trend as HCRU for these patients $(18,19)$.

Two studies directly assessed HCRU $(7,10)$ among mRCC patients. The COMPARZ non-inferiority clinical trial comparing pazopanib vs. sunitinib used selfreported health-care utilisation during follow-up appointment for HRQoL assessment. This included monthly medical visits not related to the study, telephone consultations, number of days hospitalised and number of emergency department visits for the first 6 months of follow-up. Similarly, Hansen et al. did a post-doc evaluation of the COMPARZ study comparing HCRU between the two groups for the whole follow-up period. They used the study data regarding health-care providers, laboratory and radiology use, hospitalisations, procedures and pharmacy services. The combined results of these studies showed a statistical decrease of less than 0.03 emergency and radiology visits per month of survival in favor of pazopanib compared to sunitinib. Albeit statistically significant, the difference in HCRU seen between the groups of these studies is relatively small and may be explained by the fact that both groups received targeted therapies. Also, these studies lacked objective results, since the data used were selfreported by patients and included well-selected patients for clinical trial. Our study relies 
on data directly from patients' computerised files, thus reflects objective information. Importantly this study includes unselected patients.

Although patients included in this study were treated before the publication of the 2015 Canadian consensus statement on the management of advanced kidney cancer a secondary endpoint was to evaluate concordance with these recommendations (12). The patients included in this study were treated according to current standards with sunitinib and pazopanib being the two most commonly used first-line therapy and everolimus for second-line treatment. All these molecules have Level 1 evidence status supporting their use. Since third and fourth-line treatment regimens have not yet been clearly established, the use of targeted therapies not previously used or clinical trials are the only options, which is compatible with what patients receive in this study.

Our study has several limitations. First, the small sample size may have limited the detection of small differences between groups and may under power the analyses. Second, the retrospective nature of the study represents another limitation of this study, but to our knowledge, there are no prospective studies that assessed HCRUs in mRCC in a real-world scenario besides clinical trials. Third, the heterogeneity of the groups may also undermine the validity of the comparisons. For example, within the non-treated group, some patients were considered for palliative care only while others had curative intended procedures. Fourth, real costs for HCRU and imaging use were not available for all patients to add an economic perspective to the use of health-care resources. Finally, HCRU studies should ideally assess the impact of HCRU on HRQoL. Unfortunately, economic data, costs estimation and QoL data were not available for this population.

\section{Conclusion}

Although targeted therapy-treated patients for mRCC may exhibit lower monthly use of health-care, our study shows these patients ultimately will need more health-care resources than those without any targeted therapy, due primarily to an increase survival length. 


\section{References}

1. Canadian Cancer Society. Toronto (ON): Canadian Cancer Society's Advisory Committee on Cancer Statistics; 2016 [updated 2016, cited September 12 ${ }^{\text {th }}$, 2016]. http://www.cancer.ca/en/cancer-information/cancer type/kidney/statistics/?region=qc/. Accessed September $10^{\text {th }}, 2016$

2. Cancer.net. American Society of Clinical Oncology; c2005-16 [updated May 2015; cited September $12^{\text {th }}$ 2016]. Kidney Cancer:

Statistics. http://www.cancer.net/cancer-types/kidney-cancer/statistics/. Accessed September $10^{\text {th }}, 2016$

3. Beaumont JL, Butt Z, Baladi J, Motzer RJ, et al. Patient-reported outcomes in a phase iii study of everolimus versus placebo in patients with metastatic carcinoma of the kidney that has progressed on vascular endothelial growth factor receptor tyrosine kinase inhibitor therapy. Oncologist 2011;16(5):632-40.

4. Bukowski R, Cella D, Gondek K, et al. Effects of sorafenib on symptoms and quality of life: results from a large randomized placebo-controlled study in renal cancer. Am J of Clin Oncol 2007;30(3):220-7.

5. Cella D, Davis MP, Negrier S, et al. Characterizing fatigue associated with sunitinib and its impact on health-related quality of life in patients with metastatic renal cell carcinoma. Cancer 2014;120(12):1871-80.

6. Cella D, Michaelson MD, Bushmakin AG, et al. Health-related quality of life in patients with metastatic renal cell carcinoma treated with sunitinib vs interferonalpha in a phase III trial: final results and geographical analysis. Br J Cancer 2010;102(4):658-64.

7. Cella D, Pickard AS, Duh MS, et al. Health-related quality of life in patients with advanced renal cell carcinoma receiving pazopanib or placebo in a randomised phase III trial. Eur J Cancer (Oxford, England : 1990). 2012;48(3):311-23.

8. Hansen RN, Hackshaw MD, Nagar SP, et al. Health care costs among renal cancer patients using pazopanib and sunitinib. J Manag Care Spec Pharm 2015;21(1):37-44, a-d.

9. Shih YC, Chien CR, Xu Y, Pan IW, et al. Economic burden of renal cell carcinoma: Part I - an updated review. Pharmacoeconomics 2011;29(4):315-29.

10. Shih YC, Chien CR, Xu Y, et al. Economic burden of renal cell carcinoma in the US: Part II - an updated analysis. Pharmacoeconomics 2011;29(4):331-41.

11. Motzer RJ, Hutson TE, Cella D, et al. Pazopanib versus sunitinib in metastatic renal-cell carcinoma. $N$ Engl J Med 2013;369(8):722-31.

12. Motzer RJ, Hutson TE, Tomczak P, et al. Overall survival and updated results for sunitinib compared with interferon alfa in patients with metastatic renal cell carcinoma. J Clin Oncol 2009;27(22):3584-90. 
13. North SA, Basappa N, Basiuk J, et al. Management of advanced kidney cancer: Canadian Kidney Cancer Forum consensus update. Can Urol Assoc J 2015;9(56):164-70.

14. Motzer RJ, Bacik J, Mazumdar M. Prognostic factors for survival of patients with stage IV renal cell carcinoma: memorial sloan-kettering cancer center experience. Clin Cancer Res 2004;10(18 Pt 2):6302s-3s.

15. Smyth EN, Bapat B, Ball DE, et al. Metastatic Pancreatic Adenocarcinoma Treatment Patterns, Health Care Resource Use, and Outcomes in France and the United Kingdom Between 2009 and 2012: A Retrospective Study. Clin Ther 2015;37(6):1301-16.

16. Schmidinger M, Larkin J, Ravaud A. Experience with sunitinib in the treatment of metastatic renal cell carcinoma. Ther Adv Urol 2012;4(5):253-65.

17. De Giorgi U, Scarpi E, Sacco C, et al. Standard vs adapted sunitinib regimen in elderly patients with metastatic renal cell cancer: results from a large retrospective analysis. Clin Genitourin Cancer 2014;12(3):182-9.

18. Burke JP, Liu Z, Zheng J et al. Incidence, annualized cost, and utilisation burden in patients with metastatic renal cell carcinoma, J Clin Oncol 2009; abstr e17529

19. Oh W.K., McDermott F, Duh MS et al. Healthcare costs in patients (pts) with metastatic renal cell carcinoma (mRCC) treated with angiogenesis inhibitors (AI), ASCO 2010, unpublished 
Figures and Tables

Fig. 1. Patient selection.

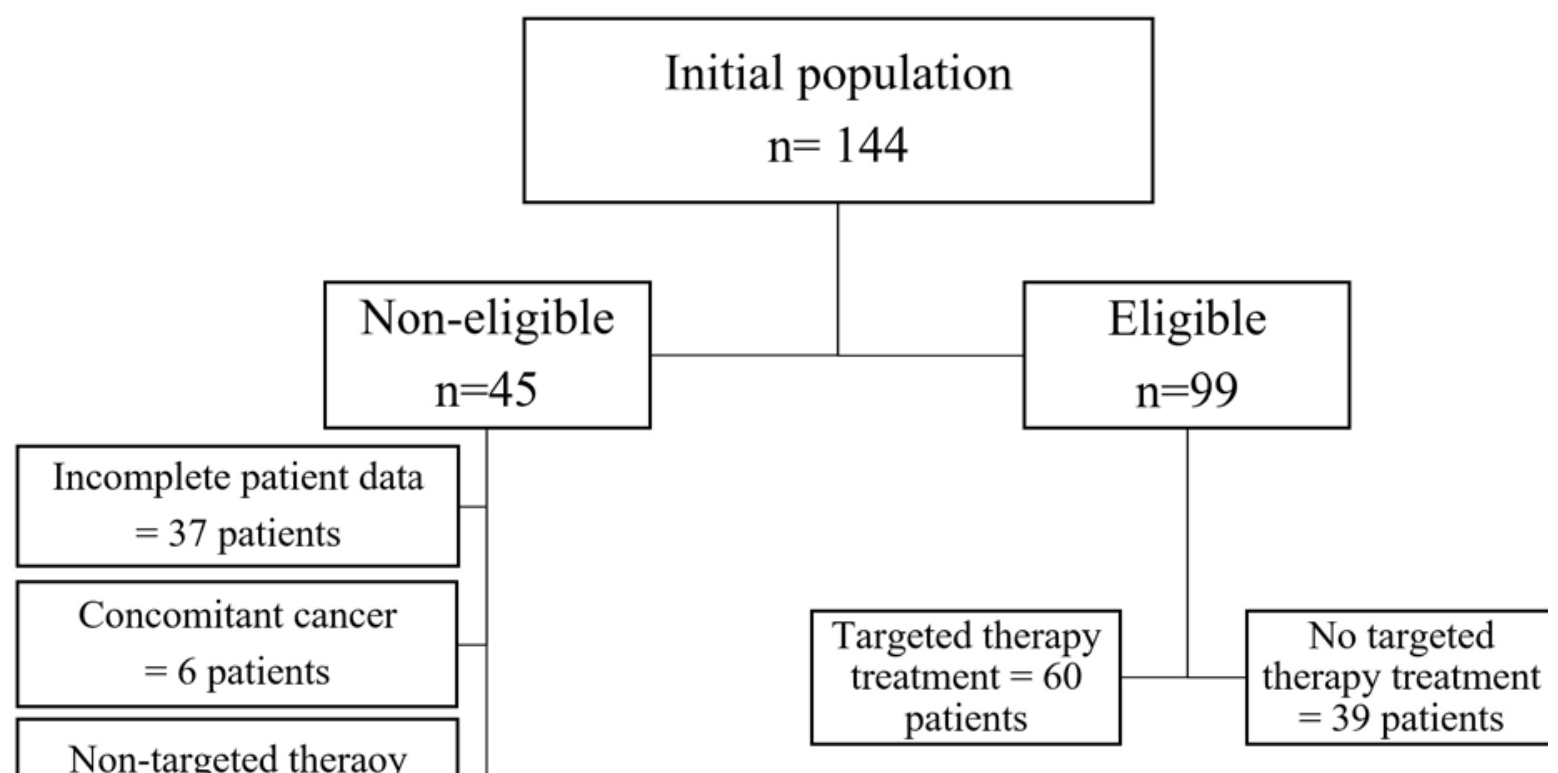

Table 1. Demographic and initial oncological data based on the use of targeted therapy

\begin{tabular}{|c|c|c|c|}
\hline 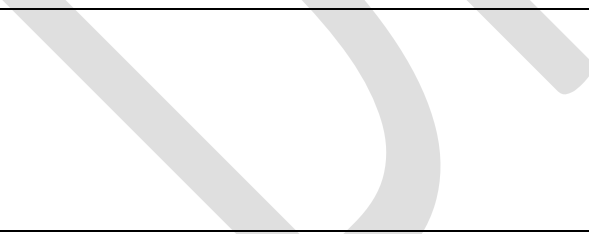 & $\begin{array}{c}\text { Targeted } \\
\text { therapy group } \\
\mathbf{n}=\mathbf{6 0}\end{array}$ & $\begin{array}{c}\text { Absence of } \\
\text { targeted therapy } \\
\text { group } \\
\text { n= } 39\end{array}$ & $\mathbf{p}$ \\
\hline $\begin{array}{l}\text { Gender } \\
\qquad \begin{array}{l}\text { Male } \\
\text { Female }\end{array}\end{array}$ & $\begin{array}{l}43 \\
17\end{array}$ & $\begin{array}{l}26 \\
13\end{array}$ & 0.60 \\
\hline Age at diagnosis, median (range) & $\begin{array}{c}63 \\
(29-101)\end{array}$ & $\begin{array}{c}66 \\
(20-90)\end{array}$ & 0.092 \\
\hline $\begin{array}{c}\text { Histology type, } \mathbf{n}(\%) \\
\text { Clear-cell } \\
\text { Chromophobe }\end{array}$ & $\begin{array}{c}50(83) \\
1(2)\end{array}$ & $\begin{array}{c}29(74) \\
2(5)\end{array}$ & 0.11 \\
\hline
\end{tabular}




\begin{tabular}{|l|c|c|c|}
\hline Papillary & $3(5)$ & $1(3)$ & \\
Mixed clear-cell/papillary & $3(5)$ & $2(5)$ & \\
Undifferentiated & $3(5)$ & $3(7)$ & \\
Sarcomatoid & $0(0)$ & $2(5)$ & \\
\hline Metastatic burden, n(\%) & & & \\
Single metastasis & $7(11)$ & $10(26)$ & 0.13 \\
Oligometastasis & $22(37)$ & $9(23)$ & \\
$\quad$ Plurimetastasis & $31(52)$ & $20(51)$ & \\
Motzer risk stratification scale, & & & \\
n(\%) $\quad$ Low & $13(22)$ & $8(20)$ & \\
Intermediate & $34(57)$ & $11(28)$ & \\
High & $10(17)$ & $11(28)$ & \\
$\quad$ Unknown & $3(5)$ & & \\
\hline
\end{tabular}

\begin{tabular}{|l|c|}
\hline \multicolumn{2}{|l|}{ Table 2. Reasons for not receiving targeted therapy } \\
\hline & Number of patients, n(\%) \\
\hline End of life state at diagnosis & $10(26)$ \\
\hline Metastasis treated with other modalities & $9(23)$ \\
\hline Patient's will & $8(20)$ \\
\hline Insufficient information & $7(18)$ \\
\hline Non-eligible for treatment & $5(13)$ \\
\hline
\end{tabular}




\begin{tabular}{|l|c|c|c|}
\hline \multicolumn{3}{|c|}{ Table 3. Median healthcare resource use based on the use of targeted therapy } \\
\hline & $\begin{array}{c}\text { Targeted therapy } \\
\text { group } \\
\text { n= 60 }\end{array}$ & $\begin{array}{c}\text { No targeted } \\
\text { therapy group } \\
\text { n= 39 }\end{array}$ & p \\
\hline Number of hospitalizations & $\begin{array}{c}1 \\
(0-5)\end{array}$ & $(0-5)$ & 0.10 \\
\hline $\begin{array}{l}\text { Number of Hospitalizations per } \\
\text { month of survival }\end{array}$ & $\begin{array}{c}0.09 \\
(0-0.79)\end{array}$ & $\begin{array}{c}0.13 \\
(0-1.69)\end{array}$ & 0.03 \\
\hline Number of days hospitalized & $\begin{array}{c}10 \\
(0-72)\end{array}$ & $\begin{array}{c}9 \\
(0-90)\end{array}$ & 0.71 \\
\hline $\begin{array}{l}\text { Number of days hospitalized per } \\
\text { months of survival }\end{array}$ & $\begin{array}{c}0,48 \\
(0-19.63)\end{array}$ & $\begin{array}{c}0,99 \\
(0-20.22)\end{array}$ & 0.21 \\
\hline Healthcare consultants & $\begin{array}{c}6 \\
(1-14)\end{array}$ & $\begin{array}{c}4 \\
(0-13)\end{array}$ & $<0.01$ \\
\hline $\begin{array}{l}\text { Healthcare consultants per month of } \\
\text { survival }\end{array}$ & $\begin{array}{c}0.33 \\
(0.029-2.18)\end{array}$ & $\begin{array}{c}0.40 \\
(0-5.93)\end{array}$ & 0.04 \\
\hline Emergency department visits & $\begin{array}{c}1 \\
(0-6)\end{array}$ & $\begin{array}{c}0 \\
(0-4)\end{array}$ & 0.02 \\
\hline $\begin{array}{l}\text { Emergency department visits per } \\
\text { month of survival }\end{array}$ & $\begin{array}{c}0.052 \\
(0-0.55)\end{array}$ & $\begin{array}{c}7.3 \\
(0-1.69)\end{array}$ & 0.44 \\
\hline Overall survival & $\begin{array}{c}16.5 \\
(2.1-71.0)\end{array}$ & $\begin{array}{c}7.3 \\
(0.8-73.9)\end{array}$ & 0.02 \\
\hline
\end{tabular}

${ }^{*}$ Data presented as median (full range). 


\begin{tabular}{|l|c|c|c|c|c|c|}
\hline \multicolumn{1}{|c|}{ Table 4. Median HCRU adjusted for Motzer risk stratification scale } \\
\hline & $\begin{array}{c}\text { Low-risk } \\
\text { Targeted } \\
\text { therapy } \\
\mathbf{n = 1 3}\end{array}$ & $\begin{array}{c}\text { No } \\
\text { targeted } \\
\text { therapy } \\
\mathbf{n = 8}\end{array}$ & $\begin{array}{c}\text { Targeted } \\
\text { therapy } \\
\mathbf{n}=\mathbf{3 4}\end{array}$ & $\begin{array}{c}\text { No } \\
\text { targeted } \\
\text { therapy } \\
\mathbf{n = 1 1}\end{array}$ & $\begin{array}{c}\text { Targeted } \\
\text { therapy } \\
\mathbf{n = 1 0}\end{array}$ & $\begin{array}{c}\text { No } \\
\text { targeted } \\
\text { therapy } \\
\mathbf{n = 9}\end{array}$ \\
\hline $\begin{array}{l}\text { Number of } \\
\text { hospitalizations } \\
\text { per month of } \\
\text { survival }\end{array}$ & 0.04 & 0.08 & 0.08 & 0.20 & 0.21 & 0.33 \\
\hline $\begin{array}{l}\text { Number of } \\
\text { consultants per } \\
\text { month of } \\
\text { survival }\end{array}$ & 0.26 & 0.13 & 0.26 & 0.59 & 0.57 & 0.67 \\
\hline $\begin{array}{l}\text { Number of } \\
\text { consultants }\end{array}$ & 5 & 4 & 5 & 4 & 6 & 3 \\
\hline $\begin{array}{l}\text { Number of } \\
\text { emergency } \\
\text { department } \\
\text { visits }\end{array}$ & 0 & 0 & 1 & 0 & 2 & 0 \\
\hline
\end{tabular}




\begin{tabular}{|l|c|}
\hline Table 5. Treatment regimen description \\
\hline Line of therapy and medication used & Number of patients (\%) \\
\hline First-line & $60(100)$ \\
Sunitinib & $45(75)$ \\
Pazopanib & $8(14)$ \\
Sorafenib & $2(3)$ \\
Everolimus & $2(3)$ \\
Temsirolimus & $2(3)$ \\
Axitinib & $1(2)$ \\
\hline Second-line & $40(66.7)$ \\
Everolimus & $20(33.3)$ \\
Sunitinib & $9(15)$ \\
Sorafenib & $9(15)$ \\
Axitinib & $2(3)$ \\
\hline Third-line & $13(21.7)$ \\
Everolimus & $5(38)$ \\
Sunitinib & $3(23)$ \\
Sorafenib & $3(23)$ \\
Axitinib & $2(16)$ \\
\hline Fourth-line & $5(8.3)$ \\
Sunitinib & $2(3.3)$ \\
Sorafenib & $2(3.3)$ \\
Axitinib & $1(1.7)$ \\
\hline
\end{tabular}

